https://www.amerabra.org; https://fspu.uitm.edu.my/cebs; https://www.emasemasresources.com/ $9^{\text {th }}$ Asian Conference on Environment-Behaviour Studies Perdana Kota Bharu, Kelantan, Malaysia, 28-29 Jul 2021

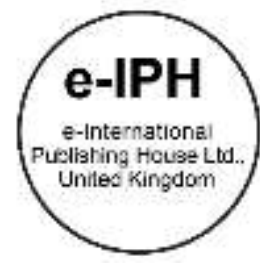

\title{
Safety Management Practices and Safety Behaviour among Outdoor Participants
}

\author{
Rozita Abdul Latif ${ }^{1}$, Muhammad Shafiq Suhaimi' ${ }^{1}$, Hisyam Che Mat', \\ Antoaneta Dimitrova ${ }^{3}$, Mohamad Wafi A Rahman'1
}

\begin{abstract}
1 Faculty of Sport Science and Recreation, Universiti Teknologi MARA, Seremban Campus, Malaysia
2 Faculty of Sport Science and Recreation, Universiti Teknologi MARA, Shah Alam Campus, Malaysia

3 University of Structural Engineering and Architecture, Sofia, Bulgaria
\end{abstract}

rozita.abdlatif@uitm.edu.my, shafiqfnatic@gmail.com, hisyam@uitm.edu.my, tonnie_d@hotmail.com, wafiarahman@uitm.edu.my Tel: 0196634788

\begin{abstract}
Safety management practices(SMPs) and safety behaviour (SB) prevent accidents and injuries in outdoor activities. The study investigated the relationship between SMPs and SB among outdoor participants. Two hundred and fifty outdoor activity participants were respondents. It administered the Vinodkumar and Bhasi questionnaire to the participants. Most respondents, comprising $49.4 \%(n=126)$, participated in outdoor activities once or twice a week. Results showed a moderate relationship between SMPs and SB $(r(255)=0.697, p<0.001)$. The study recommends that outdoor activities service providers should implement policies to safeguard participants to prevent accidents and injuries.
\end{abstract}

Keywords: Safety management practices(SMPs); safety behavior(SB); outdoor participants

eISSN: 2398-4287@ 2021. The Authors. Published for AMER ABRA cE-Bs by e-International Publishing House, Ltd., UK. This is an open-access article under the CC BYNC-ND license (http://creativecommons.org/licenses/by-nc-nd/4.0/). Peer-review under responsibility of AMER (Association of Malaysian Environment-Behavior Researchers), ABRA (Association of Behavioral Researchers on Asians/Africans/Arabians), and CE-Bs (Centre for Environment-Behavior Studies), Faculty of Architecture, Planning \& Surveying, Universiti Teknologi MARA, Malaysia.

DOI: https://doi.org/10.21834/ebpj.v6i17.2885

\subsection{Introduction}

Alor Setar Escape ZONE recreation center in Kedah, near Mount Keriang Recreational Park, organizes outdoor activities such as hiking, caving, abseiling, rock climbing, kayaking, and team building (Rahman, 2020). The area has lush greens, exotic flora, and a net of hiking routes. It is a popular area for outdoor activities, but accidents sometimes occur, and participants get hurt. An accident is an unfortunate event that happens without warning and causes an injury to a person; it can occur at any place, at any time. An accident is unintended, unforeseen, and happens to people who are unprepared for it. Victims of accidents suffer various consequences like death, injuries, diseases, property loss, and environmental damage (Cuthbert, 2020). It means training participants in outdoor activities to safely use their equipment and follow safety procedures to prevent dangerous accidents. However, managers and outdoor participants ignore the significance of safety procedures (Ladewski, 2019). Safety management (SM) for participants in outdoor activities is as important as school SM for pupils, teachers, and staff.

All parties need SM to protect them from potential dangers that can cause accidents and injuries to participants (outdoor activities) or pupils, teachers, and staff (schools). The prime aim of SM is to identify dangers that can cause accidents and remove them or set mitigating risk procedures in hazardous places to warn people of hazards to prevent accidents (Naranasamy, 2019).

eISSN: 2398-4287C 2021. The Authors. Published for AMER ABRA cE-Bs by e-International Publishing House, Ltd., UK. This is an open access article under the CC BYNC-ND license (http://creativecommons.org/licenses/by-nc-nd/4.0/). Peer-review under responsibility of AMER (Association of Malaysian Environment-Behavior Researchers), ABRA (Association of Behavioral Researchers on Asians/Africans/Arabians), and cE-Bs (Centre for Environment-Behavior Studies), Faculty of Architecture, Planning \& Surveying, Universiti Teknologi MARA, Malaysia.

DOI: https://doi.org/10.21834/ebpj.v6i17.2885 
An excellent SM routine will help the company establish robust promotional procedures; the best safety communication methods outdoors may ensure participants' safety. The management of organizations should carry out comprehensive accident reviews and annual safety checks to evaluate and improve organizations' safety policies. Risk mitigation should be at the core of the management safety process. The process should include risk recognition, evaluation, and control that guarantees safety for employees and clients. Doing this will encourage long-term company commitment to safety, leading to increased productivity (Qamruzzaman, 2020).

In recent years, many accidents have happened to people while participating in outdoor activities. For example, when hiking up the slopes of Bukit Banang, a 20-year-old woman dies (on November 14, 2020) as she falls 80 meters down into a gorge (Devi, 2020). The management could have educated her on safety procedures to avoid her death. Several accidents have happened to visitors to adventure parks and outdoor recreation destinations in Malaysia. Such accidents are also a problem worldwide (Johannis, 2016). To prevent dangers, many local authorities in Malaysia have implemented safety procedures and held campaigns to educate the public (Johannis, 2016). However, accidents are still increasing -the local authorities in Malaysia reported 134 hiking accidents (Johannis, 2016). In addition, from 1996 to 2014, 665 of the reported casualties occurred in mountain hiking activities, including 47 deaths. Besides, two students fell to death while hiking in Gunung Bubu, Kuala Kangsar, Perak (Sidi, 2019). During a training program for vocational school students at Ulu Kenas Recreational Park - two students died. In contrast, the Search and Rescue team rescued two others from Kuala Kangsar (Sidi, 2019). Afforested shows that accidents can happen anywhere. Therefore, preventive measures via safety management prevent hazardous incidents. It is essential to study all safety rules and procedures before partaking in outdoor activities to avoid accidents. This paper explored the nature of risk management procedures for outdoor activities implemented by an organization to reduce or eliminate risk. The research investigated three objectives: first, the favourite outdoor activities of the participants; second, the level of SB amongst participants; and finally, the relationship between SMPs and SB among outdoor-activity participants.

\subsection{Literature review}

Safety management is a combination of safety principles, procedures, and policies necessary to prevent accidents. It also includes rules, guidelines, strategies, events, training, communication, feedback, and promoting general knowledge in safety management. A good safety policy will fit the needs of an organization and help prevent accidents (Naranasamy, 2019). Vinodkumar and Bhasi (2010) reported that safety training was a crucial factor in maintaining safety in the workplace and helps employees to adhere to safe behaviour. Safety training is essential because it allows the outdoor-activity participants to detect dangers and find ways to avoid them (Aziz, 2019). It also includes emergency procedures to tackle indoor and outdoor accidents (Aziz, 2019). Safety training may help people deal with emergencies and adequate hazard identification and risk-control (Aziz, 2019). Safety training aims to enable people to act safely during outdoor activities to prevent accidents. It can be developed by raising awareness of safety issues, instilling safety knowledge and risk identification.

\subsection{Participation is the willingness of people to take part in a particular activity}

Outdoor participation is when people gather to take part in outdoor activities. The management can obtain higher motivation levels towards safety by the degree of participants' training in safety-related activities. Safety communication should be two-way communication between managers and participants (Mashi, 2018). Mashi (2018) observed that effective methods of frequently communicating safety principles and procedures among management and employees and providing feedback show significant differences between organizations with fewer accidents and injuries and those with rather serious ones. The implementation of safety rules and procedures controls dangers and eliminates risk.

The question here is: What are safety rules and procedures? A safety rule refers to a safety structure that explains a specific safe way of behaving when confronted with a hazardous situation. These safety rules and guidelines are made available to all stakeholders and observed by all. Safety rules explain different dangers and avoid them, and what to do when accidents and injuries occur, as the practices improve organizational safety (Vidal-Gomel, 2017). Effective safety management is vital for preserving the intercommunication between the safety policies and people, as the human factor contributes to safety efficiency.

\subsection{The safety promotion policies}

Behaviour is how one acts, whereas people respond to specific situations (Lyu, 2018). SB are actual behaviours that individuals perform. Security enforcement denotes mandatory habits while doing outdoor activities to preserve safety (Lyu, 2018). Safety promotion policies are designed to upkeep situations and are essential to avoid accidents and guarantee protection for people (Aziz, 2019). Raising awareness of safety practices in organizations has considerably reduced accidents and injuries (Aziz, 2019). Having introduced company safety policies showed that the management took preventive measures to protect all and their constructive approach to safety. Mainly, outdoor accidents and injuries among participants occur when participants do not observe safety rules and procedures. However, strict adherence and enforcement of policies to ensure safety will indeed reduce such accidents and injuries. Accidents and injuries reduce when outdoor-event partakers are fully committed to safety participation (Lyu, 2018). Moreover, by reducing workplace dangers and decreasing the number of accidents and injuries, employees' performance will likely increase (Schopf, 2021). 


\subsection{Methodology}

The research design employed techniques and a framework of research methods to collect and analyze all data. The design allowed researchers to select appropriate methods to investigate the research topic to ensure the success of their study (Bhat, 2020). The research uses the quantitative methodology for cases where statistical analysis leads to a statistical conclusion was deemed essential. The quantitative method was considered necessary for the study of safety procedures in outdoor activities.

\subsection{Sampling}

Sampling is choosing a representative unit from a larger population that matters to researchers. Studying the sample will allow them to generalize the results based on the population from which the sample was selected (Trochim, 2020). The respondents in this study were people partaking in outdoor activities. The research used purposive random sampling to select the sample. 720 was the number of outdoor-activity participants, but the sample included 250 (Krejcie \& Morgan, 1970). Male respondents were $(n=132 ; 51.8 \%)$ and females - $123(48.2 \%)$. Most respondents comprise male and female in the following ratio: 18 to 21 -year-olds $(n=78 ; 30.6 \%)$ followed by 38-year olds ( $n=61 ; 23.9), 22$ to 25 -year-olds $(n=60 ; 23.5 \%)$ and 30 to 33 -year-olds $9.0 \%(n=23)$. Others were from 26 to 37 -yearolds, which accounted for 33 respondents.

\subsection{Measurements}

The data collection used a questionnaire survey. The questionnaire was distributed through Google Form (GF), which appears a common choice for survey research (Raju \& Harinayan, 2016). Vinodkumar and Bhasi (2010) questionnaire was used. A pilot study assessed its reliability (Musa, 2018). Results yielded an alpha value of $\alpha=0.925$.

\subsection{Findings}

Male participants' favourite outdoor activity was hiking - 40 respondents (15.7\%) (Table 1). As for females, horseback riding was the most favourite one: 32 respondents (12.5\%). Hiking - preferred activity by 18-25 year-olds: 27 respondents (10.6\%). The favourite overall outdoor activity for 26-29-year-olds was rock climbing with 25 respondents (9.8\%), as for the 30-37-year-olds, it was abseiling. For 37 -year-olds and above, horseback riding was their favourite activity -15 respondents (5.9\%). Five basic outdoor recreation activities were surveyed, but most participants preferred hiking, rock climbing, and horseback riding. The majority of the respondents, $49.4 \%$, did outdoor activities 1-2 times $(n=126)$ per week. Meanwhile, $24.3 \%(n=62)$ did outdoor activities $3-4$ times weekly. More than 4-times-a-week activity occurred with $14.9 \%$ of respondents $(n=38)$. The lowest result $(n / a)$ on the frequency of doing outdoor activities represents $11.4 \%$ or- 29 of the respondents.

\begin{tabular}{|c|c|c|c|c|c|}
\hline & Rock Climbing & Kayak & Horseback riding & Hiking & Abseiling \\
\hline \multicolumn{6}{|l|}{ Gender } \\
\hline Male & $31(12.2 \%)$ & $24(9.4 \%)$ & $16(6.3 \%)$ & $40(15.7 \%)$ & $36(14.1 \%)$ \\
\hline Female & $12(4.7 \%)$ & $23(9 \%)$ & $32(12.5 \%)$ & $27(10.6 \%)$ & $14(5.5 \%)$ \\
\hline \multicolumn{6}{|l|}{ Age } \\
\hline $18-25$ & $23(9 \%)$ & $17(6.7 \%)$ & $4(1.6 \%)$ & $27(10.6 \%)$ & $19(7.5 \%)$ \\
\hline $26-29$ & $25(9.8 \%)$ & $19(7.5 \%)$ & $3(1.2 \%)$ & $20(7.8 \%)$ & $13(5 \%)$ \\
\hline $30-37$ & $6(2.4 \%)$ & $10(3.9 \%)$ & $11(4.3 \%)$ & $7(2.7 \%)$ & $15(5.9 \%)$ \\
\hline$>37$ & $4(1.6 \%)$ & $5(1.9 \%)$ & $15(5.9 \%)$ & $8(3.1 \%)$ & $4(1.6 \%)$ \\
\hline
\end{tabular}

Participants carried out outdoor adventure activities safely by relying on the safety brochure. Upon results in Table 2 - safety rules and procedures available in recreational parks can prevent accidents (e.g., wearing a helmet while cycling) was the most practised safety measure undertaken by management $(M=2.88 ; S D=0.41)$. Meanwhile, the public appeared not interested in knowing security issues; it recorded the lowest action taken by management in safety practices $(M=1.53 ; S D=0.59)$ (Table 2). Safety rules and procedures are vital factors that outdoor participants need to follow.

Table 3 illustrates the SB of participants. Highest result: "...I safely do outdoor activities..." (M= 2.92, SD=0.37). " "..I play the phone while doing outdoor activities..." (M=1.27; SD=0.46) - lowest.

Table 2. SMPs across outdoor participants

\begin{tabular}{lc}
\hline & Mean \\
\hline $\begin{array}{l}\text { Safety rules and procedures available in recreational parks can prevent accidents (wearing a helmet } \\
\text { while cycling) }\end{array}$ & 2.88 \\
Signage rules indicate the steps to follow when carrying out activities & 2.86 \\
Management provides adequate personal protective equipment to the public (helmets for rock & 0.41 \\
$\quad$ climbing) & 2.85 \\
The rules and procedures found in this recreational park are valuable and effective & 2.85 \\
Management always receives opinions from the public before making final decisions on security & 0.42 \\
$\quad$ measures & 2.82 \\
Management is concerned about the safety of the people who perform activities in recreational parks & 2.80 \\
Management emphasizes the level of public safety when doing outdoor activities in recreational & 0.43 \\
\hline
\end{tabular}




\begin{tabular}{lcc}
\hline parks. & 2.78 & 0.49 \\
The public follows and practices safety rules and procedures & 2.65 \\
Management takes appropriate action when there is an accident against the public at a recreational & 0.54 \\
$\quad$ park & 2.60 \\
I feel that management agrees on security to increase public satisfaction & 2.60 & 0.55 \\
Management strives to perform safety work procedures (management monitors closely) & 2.56 \\
Management considers protection as necessary as satisfaction & 2.52 \\
When an accident is imminent, the administration acts quickly to resolve the issue & 2.51 \\
Management obtains feedback from the public on safety when conducting outdoor activities & 2.47 \\
Management has experience in the protection of outdoor activities & 2.39 & 0.55 \\
Management does not care about safety in recreational parks & 1.61 & 0.56 \\
The public is not interested in knowing security issues & 1.53 & 0.56 \\
\hline
\end{tabular}

\begin{tabular}{lcc}
\multicolumn{1}{c}{ Table 3. SB factor among outdoor participants } & Mean \\
\hline & 2.92 & 0.37 \\
\hline I do outdoor activities in a safe way & 2.90 \\
I make sure no injuries occur while doing outdoor activities. & 2.89 \\
I follow safety rules and procedures while doing outdoor activities & 2.88 \\
I use and maintain the facilities available in the recreation park & 2.87 \\
I cycled using the proper path in the recreation park & 2.77 \\
I help my friends when they do outdoor activities & 2.74 \\
I always tell the management if there is a security problem & 2.26 \\
I invite my friends to participate in outdoor activities & 2.20 \\
I do activities voluntarily & 2.18 \\
I wear bright clothes while doing outdoor activities & 0.49 \\
It is not essential to follow all safety rules and procedures while participating in outdoor activities & 0.41 \\
I play the phone while doing outdoor activities & 0.49 \\
\hline
\end{tabular}

Correlation test analysis was used to answer question three. Table 4 shows the range of correlation.

Table 4. Relationship between SMPs and SB

\begin{tabular}{ccc}
\hline & & Safety Behavior \\
\hline Safety Management Practices & Person correlation & $0.697^{* *}$ \\
& Sig (2-tailed) & 0.00 \\
$\mathrm{~N}$ & 255 \\
\hline
\end{tabular}

${ }^{* *}$ Significant at the 0.01 level (2-tailed).

SMPs and how they promoted SB among participants were moderately correlated $(r(255)=0.697, p<0.001)$. The correlation showed that there was a significant relationship between SMPs and SB.

\subsection{Discussion}

\subsection{SMPs and SB among outdoor participants}

When implemented in recreation parks, safety rules and procedures can prevent accidents (e.g., wearing a helmet while cycling). SMPs in Escape Zone is pretty promising $(M=2.54)$ when emphasizing safety rules $(M=2.88)$, reminding users to behave safely by placing signs $(M=2.86)$, and when supplying outdoor safety equipment $(M=2.86)$. Safety rules and procedures are critical factors of SMPs to be observed by outdoor activities participants. According to Vinodkumar and Bhasi (2010), introducing SMPs has a significant correlation with safety behaviour. Accident-prevention measures should be documented and implemented to reduce accidents and injuries to outdoor-activity participants. Therefore, risk management standards are fundamental to reduce accidents and injuries to participants in outdoor activities (Aziz, 2019).

\subsection{SB and outdoor participants}

A mean value of 2.92 (Table 3) reflecting safety behaviour data has indicated a high level of consistency, e.g., "I safely do outdoor activities." In the meantime, decent safety practices will lead to positive safety results. Improved safety habits may lead to decreasing the number of near-misses and accidents. The number of accidents and injuries resulting from breaching safety policies is likely to be reduced by a higher degree of safety rules enforcement. Significant factors contributing to positive safety compliance behaviour were management commitment, security coordination, safety control, efficient safety instruction, safety laws and regulations, safety management system, an incentive for safety, safety, health officers, and personal protective equipment (Hassan, 2019). Safety compliance was the factor reflecting safety behaviour in outdoor participation.

\subsection{Relationship between SMPs and SB among participants in outdoor activities}

There was a moderate correlation between SMPs (management commitment, outdoor participation involvement, safety rules, and procedures) and SB ( $r(255)=0.697, p<0.001)$. According to Musa (2018), the value $r=0.697$ indicates a moderate correlation. The 
results were similar to a study by Vinodkumar (2015), which found that management's pledge to ensure safety in an organization and implement safety measures predicted safety compliance directly. However, safety measures of training, communication, and feedback indicated safety compliance indirectly. These results showed that the implementation of safety management practices leads to changes in safety efficiency (Vinodkumar, 2015).

\subsection{Conclusion}

The findings of this research may serve as applicable for practices involving the personnel, participants, and organization. Zero accidents and good quality services should be the primary objective of each organization. The safety of users should also be of paramount importance and taken into serious consideration. The equal engagement of management and users should be mandatory, for safety-and-risk-management awareness, skills, and attitude are developed by putting theory into practice. Management policy and rules must be clear, transparent, disseminated, and easily accessible to all users.

For the outdoor participants, the service providers should conduct various mini-workshops and short-term courses. Another main task is that pamphlets and posters should be prepared and distributed to the facilities. Additionally, safety aspects regarding the usage of the facilities should be made available as in print so in soft-copies on websites. Nowadays, young people are gadget-savvy, and this calls for the management to make the entire information broadly accessible and interactive on social media. Although Facebook, Twitter, and Instagram are preferred platforms, the use of other media are encouraged. In this way, such critical information will help alert the young generations on safe behaviour during exercise and using sports facilities or outdoor environments.

This safety information will reduce the probability of dangerous incidents. Management needs to implement safety plans, show commitment, grant funds, and enforcements, and make changes in company policies to enhance the managerial implementation of safety regulations to create a culture of safety behaviour in the recreation parks. We hope that our research and recommendations would provide company management with strategies to reduce accidents amongst outdoor participants.

\section{Acknowledgments}

Thank you, Dr. Kwame-Ampofo Boateng and Dr. Angie, for editing the article.

\section{Paper Contribution to Related Field of Study}

This study could be a guideline for outdoor activities administrators to emphasize the importance of safety procedures in managing outdoor activities as a preventive action.

\section{References}

Ashour, A. (2019). The Role of the Work Environment on the Safety Performance and Safety Management Practices: Its Influence on Nurses' Attitudes in the Jordanian Hospitals. American Journal of Applied Sciences, 4.

Aziz, I. S. (2019). Safety Management Practices and Safety Behavior: A Study in Manufacturing Industry in Kulim Hi-Tech Park. Research Gate, 7.

Cuthbert, S. (2020, August 31). Safeopedia. Retrieved from safeopedia.com: https://www.safeopedia.com/definition/204/accident.

Goel, A. (2019, October 24). What is the Meaning of Scope and Delimitations of a Study? Retrieved from editage.com: https://www.editage.com/insights/what-meaningscope-and-delimitations-study.

Hassan, Z. (2019). The Relationship between Supervisor Safety, Safety Management Practices, and Safety Compliance Behavior among Employees. Sains Humanika, $31-36$.

Ikau, R. A. (2019). A Preliminary Study of Safety Management Practices on Pan-Borneo Highway Construction Sites in Kuching. Malaysia. Journal of Physics: Conference Series, 3.

Ladewski, B. J. (2019). Quality and Safety Management Practices: The Theory of Quality Management Approach. Journal of Safety Research, 2.

Lyu, S. (2018). Relationships among Safety Climate, Safety Behavior, and Safety Outcomes for Ethnic Minority Construction Workers. Environmental Research and Public Health, 4 .

Mashi, M. S. (2018). The Effect of Management Commitment to Safety, and Safety Communication and Feedback on Safety Behavior of Nurses: The Moderating Role of Consideration of Future Safety Consequences. The International Journal of Human Resource Management, 8-9.

Musa, M. A. (2018). The Relationship of Safety Management Practice toward Safety Behavior Among UUM Student-Athletes. 43.

Naranasamy, K. (2019). The Relationship between Safety Management, Transformational Leadership and Safety Performance in National Primary Schools in Selangor, Malaysia. Educational Leader (Pemimpin Pendidikan), 2.

Pei, L. S. (2017). Relationship between Safety Management Practices and Safety Behavior Among Production Workers in Steel Drum Company. 30. 
Rahman. (2020). Escape_Zone_Kedah. Retrieved from Picuki: https://www.picuki.com/profile/escape_zone_kedah

Razali, N. A. (2018). A Study on Safety Management Practices and Safety Performance. The European Proceedings of Social \& Behavioral Sciences, 2.

Schopf, A. K. (2021). The Role of Leadership in Air Traffic Safety Employees' Safety Behavior. Elsevier, 2.

Shuen, Y. S. (2018). Safety Communication, Safety Culture, and Safety Leadership on Safety Participation among Manufacturing Employees. Management, 30.

Subramaniam, C. (2016). Safety Management Practices and Safety Compliance: A Model for SMEs in Malaysia. International Soft Science Conference, 5.

Taufek, F. H. (2016). Safety and Health Practices and Injury Management in Manufacturing Industry. Elsevier, 3-4.

Trochim, P. W. (2020). Sampling. Retrieved from Research Methods Knowledge Base: https://conjointly.com/kb/sampling-inresearch/\#: :text=Sampling,from $\% 20$ which $\% 20$ they $\% 20$ were $\% 20$ chosen.

Vara, J. L. (2020). An Empirical Evaluation of the Use of Models to Improve the Understanding of Safety Compliance Needs. Research Gate, 3.

Vinodkumar, M. (2015). Safety Management Practices and Safety Behavior: Assessing the Mediating Role of Safety Knowledge and Motivation. Elsevier, 10.

Yan, J. (2019). A Generic Space Definition Framework to Support Seamless Indoor/Outdoor Navigation Systems, Research Gate, 3. 